COMPOUNDS OF NOVEI STRUCTURE HAVING KAPPA-AGONIST BEHAVIORAL EFFECTS IN RHESUS MONKEYS

${ }^{1}$ Jonathan L. Katz, James H. Woods, Gail D. Winger and

${ }^{2}$ Arthur E. Jacobson

${ }^{1}$ Department of Pharmacology

University of Michigan Ann Arbor, MI 48109

${ }^{2}$ Medicinal Chemistry Section, Laboratory of Chemistry

National Institute of Arthritis, Diabetes and Digestive and Kidney Diseases National Institutes of Health Bethesda, MD

(Received in final form June 14, 1982)

\title{
Summary
}

The kappa-agonist behavioral effects of several compounds were studied in rhesus monkeys and mice. Rhesus monkeys trained to discriminate ethylketazocine from saline responded as if ethylketazocine had been administered when given bridged oripavines with either $\mathrm{N}$-allyl or $\mathrm{N}$-cyclopropylmethyl, but not $\mathrm{N}-$ methyl, substituents. These compounds had $C_{7}$ substitutions of either 2-hydroxy-2-pentyl or 2-hydroxy-5-methyl-2-hexyl. Monkeys also showed ethylketazocine-like responding when given U-50,488 (trans-3,4-dichloro-N-methyl-N-[2- (1-pyrrolidinyl) cyclohexyl]benzeneacetamide), a compound with an atypical structure not resembling any known narcotic. Additionally, ethylketazocinelike responding was produced by two 5,9-alpha dimethyl 6-7-benzomorphans with either an N-2-methoxyisobutyl or an N-2-methoxypropyl substituent. The latter compound was the only compound active in producing ethylketazocine-like discriminative effects that also reversed morphine-withdrawal signs. The N-methyl bridged oripavines that were inactive in producing ethylketazocine-like discriminative effects reversed morphine withdrawal signs.

Behavioral effects of narcotics have most clearly differentiated those presumed to be acting primarily on kappa receptors from those presumed to be acting primarily on mu receptors. For example, ethylketazocine neither suppresses nor precipitates a withdrawal syndrome in morphine-dependent dogs (1) and monkeys (2). Additionally, the direct agonist actions of ethylketazocine on behavior are clearly distinctive from those of morphine in the dog $(1,3)$ as well as the monkey (2). Recent studies have shown drug-discrimination behavioral techniques in the rhesus monkey to differentiate quite effectively compounds with mu or kappa-agonist activity (4). For example, monkeys trained to make one response after etorphine administration and a different response after saline administration, respond as if they received etorphine after administration of several mu agonists, such as morphine, but respond as if saline were administered when given ethylketazocine 
(5). Conversely, monkeys trained similarly, but with ethylketazocine rather than etorphine, respond as if given ethylketazocine after administration of kappa agonists, such as ketazocine, but as if saline were administered when given mu agonists such as morphine (6).

Most compounds previously identified as having kappa agonist activity have been of the benzomorphan structural class. We now report a compound with actions like ethylketazocine but structurally unrelated to known narcotics. Additionally, we report several bridged oripavines as well as two recently identified benzomorphans that have actions like ethylketazocine.

\section{MATERTALS AND METHODS}

The subjects were experimentally naive rhesus monkeys maintained at about $90 \%$ of their unrestricted feeding weights. During experimental sessions the subjects were restrained in primate chairs that were placed within isolation chambers facing a panel that contained stimulus lights, two response keys, and a receptacle into which food pellets could be dispensed. The subjects were trained with food reinforcement to make 100 consecutive responses on the left key following ethylketazocine $(3.0 \mathrm{ug} / \mathrm{kg})$ injection and 100 consecutive responses on the right key following saline injection. When responding was well trained and less than ten percent of the responses were on the inappropriate response key, testing of new drugs was initiated. During test sessions, 100 consecutive responses on either key produced food. Fach drug was tested over a range of doses that were administered cumulatively within a single daily session. Ten minutes after each dose, stimulus lights in the chamber were illuminated and the subject could respond on either key until 100

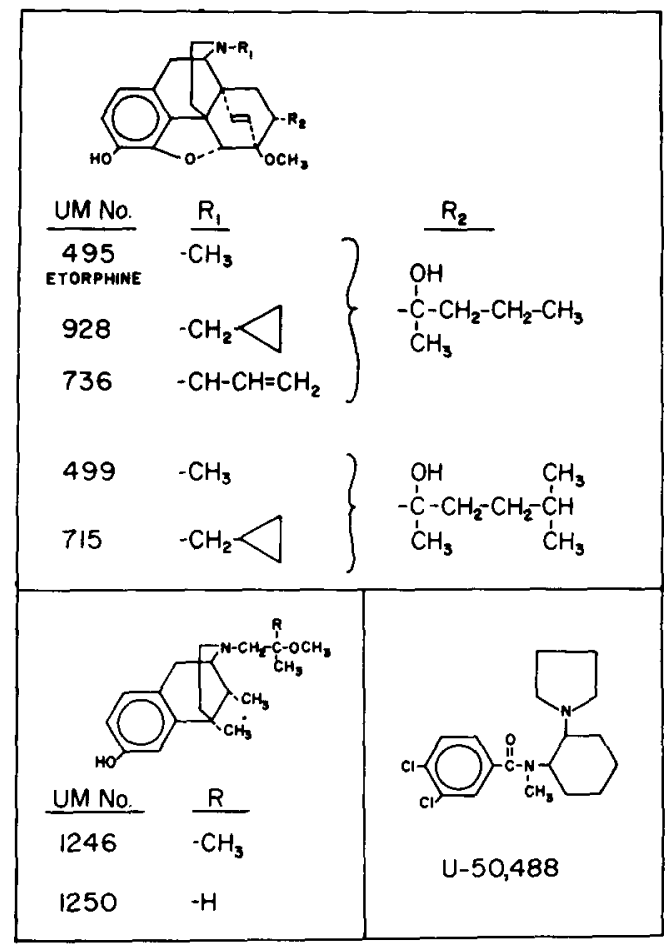

Figure 1

Structures of compounds studied in the present experiment 
consecutive responses produced food or 3 minutes elapsed. If a drug suppressed behavior to the extent that 3 minutes elapsed before completion of 100 responses, the daily session was terminated. For more details of the training and testing procedures see (7).

Rhesus monkeys maintained on morphine $(3 \mathrm{mg} / \mathrm{kg} / 6 \mathrm{hr}$ ) were occasionally withdrawn from morphine for 14 hours and single doses of drugs were tested for suppression or exacerbation of withdrawal signs according to procedures outlined by Deneau and Seevers (8) and Villarreal (9).

Male mice weighing about $20 \mathrm{~g}$, bred in-house at. NIH, were tested, eight per dose level, on a hot plate at $55^{\circ} \mathrm{C}$. A mouse was considered a positive respondent if its tine to lift its hind paws was at least five seconds greater than its longest reaction time when not drugced, over two consecutive trial periods. The number of positive respondents at each dose was used to determine the ED50 by probit analysis. For details see (10) .

The following drugs were used: ethylketazocine methane sulfonate (courtesy of $\mathrm{Dr}$. W. Michne, Sterling Winthrop) was dissolved in sterile water to which a small amount of lactic acid was added. The structures of other compounds are given in Figure 1. The forms are as follows: UTi 715 - HCl, UM 736 - base; UM 928 - HCl salt; UM 1246 - base; UM 1250 - $\mathrm{HBr}$ salt; U-50,488 $\mathrm{HCl}$ (courtesy of Dr. P. von Voigtlander, Upjohn); etorphine (UM 495) - HCI salt; UM $499-\mathrm{HCl}$ salt. $\mathrm{AIl}$ of the compounds except U-50,488 were $(-)$-isomers; U-50,488 was the racemate.

\section{PESUIJTS AND DISCUSSION}

All of the compounds except the N-methyl analogues (etorphine and UM 499) produced ethylketazocine-like discriminative effects (Table 1). There was little variation in potency among the four most potent compounds. The compound with the most novel structure, U-50,488, was the least potent. The active bridged oripavines are noteworthy in that thev had a very long duration of action. For example, suppression of behavior following $3.0 \mathrm{ug} / \mathrm{kg}$ of UN! 715 lasted two days.

\section{TARIE 1}

Potencies of Narcotics Relative to Ethylketazocine $(3.0 \mathrm{ug} / \mathrm{kg})$

\begin{tabular}{|c|c|c|c|}
\hline \multirow[b]{3}{*}{ Compound } & \multicolumn{2}{|c|}{ Rhesus Monkey } & \multirow{3}{*}{$\frac{\text { Mouse }}{\text { Analgesic }}$ Effects } \\
\hline & FKC-Discriminative & Sedative & \\
\hline & Effects & Effects & \\
\hline UM 1250 & 1.7 & 5.9 & 22.5 \\
\hline UM 715 & 1.0 & 10.0 & 9.0 \\
\hline UM 928 & 0.7 & 0.8 & 90.0 \\
\hline UM 1246 & 0.6 & 0.5 & 0.2 \\
\hline UM 736 & 0.2 & 1.0 & 0.9 \\
\hline$U-50,488$ & 0.01 & 0.1 & 0.02 \\
\hline Etorphine & $I A^{\star}$ & 40.0 & 187.5 \\
\hline UM 499 & TA & 40.0 & 98.4 \\
\hline
\end{tabular}

\footnotetext{
*IA-Inactive up to doses (Etorphine: $3.0 \mathrm{ug} / \mathrm{kg}, \overline{\mathrm{UN}} 499: 1.0 \mathrm{ug} / \mathrm{kg}$ ) that suppressed responding
}

The N-methyl analogues were quite potent in reversing withdrawal signs in morphine-dependent rhesus monkeys. Etorphine was 3000 times, and UM 4991500 times, was potent than morphine. Generally, the compounds that produced ethylketazocine-like discriminative effects did not suppress withdrawal signs in 
the 14-hour withdrawn monkey. Rather, these compounds produced a sedative effect that was characterized by ptosis, mydriasis, ataxia, and a decreased responsivity to stimuli from cage mates and human observers. The same sedative effects in normal subjects were typically antagonized by naloxone. There was more variation in potencies for producing sedative effects, and the rank order of these potencies was not the same as that for producing ethylketazocine-like discriminative effects.

Three compounds, etorphine, UM 499 and UM 1250, both suppressed withdrawal and produced sedation. Etorphine and UM 499 produced sedation at doses greater than those that reversed withdrawal signs. In contrast, UM 1250 produced sedation at doses below those that reversed withdrawal signs. This compound is the only one that reversed withdrawal signs and produced ethylketazocine-like di.scriminative effects.

All of the drugs tested had analgesic effects in the hot plate test with mice. The most potent compound was etorphine and least potent U-50,488 which was also very short acting. Notable was UM 928, which was about equipotent to ethylketazocine in discriminative and sedative effects, but 90 times more potent in producing analgesia. Of the compounds with ethylketazocine-like discriminative effects, UM 928 had the greatest separation of analgesic activity from the other actions.

These novel compounds with kappa-agonist actions have both practical and theoretical import. The long durations of action of the bridged oripavines can be exploited in studies of tolerance and dependence to kappa agonists. Previously identified kappa agonists have such short durations of action that it is difficult to maintain high enough tissue levels to confer a significant amount of tolerance. Additionally, the present data suggest that a previous supposition, that only compounds with a benzomorphan structure are kappa agonists (Chang et al., 1981), is incorrect. The variations in structures that are capable of acting as kappa agonists may help in elucidating more clearly structural requirements for kappa agonist activity.

\section{ACKNOWILDGENANTS}

Preparation of this manuscript was supported by USPHS grants DA-00154 and DA-00254. We thank D.D. Krohn for comments on the manuscript and Ms. K. Johnson for help in preparing the text.

\section{REFERENCES}

1. P.E. GIIBERT and W.R. MARTIN, J. Pharmacol. Exp. Ther. 198 66-82 (1976).

2. H.H. SWATN and M.H. SEEVERS, Proc. 36th Ann Meet, CPDD, NÄS-NRC (1974).

3. W.R. MARTIN, C.G. EADES, J.A. THOMPSON, R.E. HUPPLER and P.E. GILBERT, J. Pharmacol. Exp. Ther. 197 517-532 (1976).

4. S. HFRLING and J.H. WOOODS, Life Sci. 28 1571-1584 (1981).

5. S. HERLING and J.H. WDODS, Psychopharm. 72 265-267 (1981).

6. D.W. HEIN, A.M. YOUNG, S. HERIJING and J. Ther. 218 7-15 (1981).

7. A.J. BERTALIMIO, S. HERIING, R.Y. HAMPTON, G. WINGER and J.H. WOODS, J. Phamacol. Meth. (in press).

8. G.A. DFNEAU and M.H. SEEVERS, Proc. 25th Ann Meet, CPDD, NAS, (1963) Addendum 25.

9. J.E. VILLARREAL, Agonist and Antagonist Actions of Narcotic Analagesic Drugs, H.W. Kosterlitz, H.O.J. Collier and J.E. Villarreal, eds. p. 73-93, University Park Press, Baltimore (1973).

10. L. ATWEII and A.E. JACOBSON, Lab. Animal 7 42-47 (1978).

11. K-J.CHANG, E. HAZUM and P. CUATFECASAS, Proc. Nat. Acad. Sci. 78 4141-4145 (1981). 